\title{
BMJ
}

\section{The association between BMI and mortality using offspring BMI as an indicator of own BMI: large intergenerational mortality study}

\author{
George Davey Smith, professor of clinical epidemiology , Jonathan AC Sterne, professor of medical statistics \\ and epidemiology, ${ }^{2}$ Abigail Fraser, Medical Research Council postdoctoral fellow in health services research \\ and health of the public, ${ }^{1}$ Per Tynelius, statistician , , Debbie A Lawlor, professor of epidemiology , \\ Finn Rasmussen, professor ${ }^{3}$
}

${ }^{1}$ Medical Research Council Centre for Causal Analyses in Translational Epidemiology, Department of Social Medicine, University of Bristol, Bristol, BS8 2BN

${ }^{2}$ Department of Social Medicine, University of Bristol, Bristol, BS8 2PR

${ }^{3}$ Department of Public Health Sciences, Karolinska Institute, S-171 76 Stockholm, Sweden Correspondence to $\mathrm{F}$ Rasmussen finn.rasmussen@ki.se

Cite this as: $B M J$ 2009;339:b5043 doi:10.1136/bmj.b5043

\section{ABSTRACT}

Objectives To obtain valid estimates of the association between body mass index (BMI) and mortality by using offspring BMI as an instrumental variable for own BMI.

Design Cohort study based on record linkage, with 50 years of follow-up for mortality. Associations of offspring BMI with all cause and cause specific maternal and paternal mortality were estimated as hazard ratios per standard deviation of offspring BMI.

Setting A large intergenerational prospective population based database covering the general population of Sweden.

Participants More than one million Swedish parent-son pairs.

Results The final dataset analysed contained information on 1018012 mother-son pairs (122677 maternal deaths) and 1004617 father-son pairs (242126 paternal deaths). For some causes of death, the patterns of associations between offspring BMI and mortality were similar to those seen for own BMI and mortality in previous studies. Parental mortality from diabetes, coronary heart disease, and kidney cancer had the strongest positive associations with offspring BMI (for example, hazard ratio (HR) for coronary heart disease per standard deviation increase in offspring BMI for mothers $1.15,95 \% \mathrm{Cl} 1.14$ to 1.17 and for fathers $1.10,1.09$ to 1.11). However, in contrast to the inverse association of own BMI with lung cancer and respiratory disease mortality seen in other studies, there was a positive association between offspring BMI and lung cancer mortality in mothers $(1.12,1.09$ to 1.15$)$ and fathers $(1.03,1.02$ to 1.05$)$ and between offspring BMI and respiratory mortality in mothers $(1.05,1.02$ to 1.08$)$ and fathers $(1.02,1.00$ to 1.04). Associations of own BMI and offspring BMI with all cause, cardiovascular disease related, and non-cardiovascular disease related mortality were compared in a subset of father-son pairs ( $n=72815)$. When offspring BMI was used as an instrumental variable for paternal BMI, the causal association between BMI and paternal cardiovascular disease mortality (HR per standard deviation of $\mathrm{BMI} 1.82,95 \% \mathrm{Cl} 1.17$ to 2.83 ) was stronger than that indicated by the directly observed association between own BMI and cardiovascular disease mortality $(1.45,1.31$ to 1.61$)$.

Conclusions Use of offspring BMI as a predictor of own $\mathrm{BMI}$, a technique that avoids problems of reverse causality, suggests that positive associations of BMI with all cause and cardiovascular mortality may be underestimated in conventional observational studies. Use of offspring BMI instead of own BMI in analyses of respiratory disease and lung cancer mortality, for which previous studies have reported consistent and strong inverse associations with own BMI, suggests that such studies have overstated the apparent adverse consequences of lower BMI with respect to these outcomes.

\section{INTRODUCTION}

Both the prevalence of obesity and average body mass index (BMI) are rising rapidly in industrialised countries. Academic and governmental agencies predict that these increases will generate adverse trends in the incidence of, and mortality from, diseases considered to be related to obesity, such as diabetes, coronary heart disease, stroke, and many cancers. Commentators in both the academic ${ }^{1-3}$ and popular ${ }^{4}$ literature, however, have pointed to inconsistencies in the evidence that overweight and obesity are causally related to increased all cause mortality.

A large number of studies have demonstrated a $\mathrm{U}$ shaped association between BMI and mortality, with the highest mortality risk in people who are in the most underweight and most overweight groups. ${ }^{5-15}$ With this type of pattern, it is unclear whether shifting the entire distribution downwards - the key population based prevention strategy for many chronic diseases ${ }^{16}$ — would actually generate an overall beneficial effect on mortality. Indeed, some calculations to this effect have suggested the reverse; for example, in the US an increase in BMI over the 20th century has been claimed to be responsible for a considerable proportion of the decline in mortality during the century. ${ }^{17}$ 
Table 1|Assumptions in an instrumental variable analysis and how they are met in this study

\section{Assumption}

The instrumental variable is

associated with the risk factor of

interest

The instrumental variable is not

influenced by the outcome

The instrumental variable is not associated with confounding factors
In our study and other published studies, offspring BMI is positively associated with parental BM

Parental mortality cannot plausibly affect variation in offspring BMI. Thus, our instrumental variable analysis cannot be affected by reverse causality

It is possible in our example that characteristics such as parental ill health, parental diet, physical activity, and smoking status might be associated with offspring BMI as well as with the parent's BMI and mortality. However, these associations are likely to be weaker for offspring BMI than they are for parental BMI

Other than via its association with the This is usually difficult to prove in any instrumental variable analysis, risk factor of interest, there is no other but aside from the possible residual confounding mentioned above, we pathway linking the instrumental variable with the outcome of interest cannot think of any reason why offspring BMI should be related to

parental mortality, other than through its association with parental BMI
Some researchers have argued that the apparent $\mathrm{U}$ shaped curve provides a biased assessment of the causal association between BMI and mortality. In particular, confounding by factors such as smoking, other health related behaviours, and poor socioeconomic circumstances might generate an apparently high mortality risk among underweight people. Furthermore, weight loss as a result of disease means that thin people might have a higher mortality risk than their fatter counterparts. ${ }^{6111819}$

A variety of approaches to the problems of confounding and reverse causality in the BMI-mortality relation have been advocated. Firstly, the first few years of follow-up in any study can be excluded because deaths in this period will be strongly influenced by illness, leading to a higher mortality risk. Secondly, the presence of illness at baseline and confounding factors such as smoking and poor socioeconomic circumstances can be statistically adjusted for or affected subgroups can be excluded from analyses. However, all these approaches have potentially serious limitations; for example, measurement error with respect to confounding factors can lead to residual confounding ${ }^{20}$ and potentially to overestimation of the association..$^{21}$ Furthermore, illnesses that lead to lower BMI could also generate an inverse association between BMI and mortality over a long follow-up period. ${ }^{1819}$

As Seidell and colleagues comment, ${ }^{18}$ it is unlikely that the issue of BMI and mortality will ever be resolved by randomised controlled trials. Given the potential importance of obesity and overweight as a cause of poor population health outcomes, it is imperative that valid estimates of causal effects are obtained.

One promising approach to this problem is the use of instrumental variables. ${ }^{22}$ Briefly, an instrumental variable is a variable that is associated with a risk factor of interest (in this case own BMI) and is only associated with the outcome of interest (here all cause and cause specific mortality) because of its association with the risk factor of interest. In an instrumental variable analysis, the component of variation within a risk factor that is explained by the instrumental variable is used to provide an unbiased and unconfounded assessment of the causal association between the risk factor of interest and the outcome.

With respect to BMI, illness that produces weight loss is probably the most important factor that could cause observational associations to be biased indicators of causal effects. An instrumental variable in this case is one that is reliably related to BMI but is not related to disease that might influence $\mathrm{BMI} .^{23}$ One such variable is the BMI of the offspring of individuals whose mortality risk is being examined. The accuracy of an instrumental variable analysis relies on not violating a set of assumptions (table 1).

The associations between the BMI of parents and the BMI of offspring are similar regardless of whether mothers' BMI or fathers' BMI is used. ${ }^{2425}$ Clearly, illness among fathers will not directly influence the BMI of their offspring. On the other hand, illness among mothers could influence fetal growth and then possibly later BMI of offspring, particularly if the illness predates pregnancy. However, the degree of reverse causation will probably be less if offspring BMI is related to mortality than if own BMI is used. Confounding could still exist if offspring BMI is used in an analysis, in particular if mother-offspring pairs are used, because exposures such as smoking during pregnancy may be associated with offspring BMI. Such confounding is likely to lead to differences in the offspring BMIparental mortality associations in mothers compared with fathers.

One previous study has used offspring BMI as an instrumental variable to investigate the causal association of overweight on employment disability. ${ }^{22}$ This study suggested that the usual approach of associating the BMI of individuals to their risk of employment disability overestimates the strength of the association.

In the present study, we analyse a large intergenerational prospective database to estimate causal effects of BMI on mortality by using offspring BMI as an instrumental variable for own BMI.

\section{METHODS}

As previously described, ${ }^{2627}$ the Swedish Multi-Generation Register was used to identify all 1620571 male children born in Sweden between 1951 and 1980, and their biological parents. In total 1617103 respective mothers and 1594766 respective fathers were identified using the unique individual identity numbers given to all citizens and individuals with permanent permission to live in Sweden. This number was also used to link to and extract data from several other national registers.

Between 1969 and 2002, a total of 1343349 (83\%) of the male offspring identified had their height, weight, and systolic and diastolic blood pressures measured at conscription examinations. These examinations are mandatory by law for all young male Swedish citizens, and they predate active military service; that is, they are also conducted for males who do not later enter military service. During the years covered by this study, only males with severe handicap or a chronic disease were exempted from the conscription 
examination. The men in our study were aged between 17 years and 25 years old at these examinations (mean age 18.3 years); $92 \%$ were 17 years or 18 years of age. Data were missing for around $17 \%$ of males, mainly because of accidental loss of data from 1978, 1984, and 1985 owing to changes in data management at the conscription authority.

Data on parents' educational level were derived from the Population and Housing Census of 1970 and were coded in five categories: less than 9 years; 9-10 years; full secondary; higher; or missing. Data on parents' occupational and social class were derived from the Population and Housing Census of 1970 and were coded into five categories as: non-manual high/ intermediate; non-manual low; skilled manual; unskilled manual; and other/missing. In addition, data on height, weight, and systolic blood pressure recorded at conscription examinations between 1969 and 1985 were available for 95152 fathers. Data on smoking habits were available for 22929 fathers undergoing conscription examinations between 1969 and 1970 and for 36307 offspring.

A linkage was made between conscription records and parents' death records (date of death and international classification of diseases 7, 8, 9, or 10 codes) contained in the Swedish Cause of Death Register for deaths up to 31 December 2001. The deaths of 181202 mothers and 368542 fathers had been recorded by that date.

The outcome variables were all cause and cause specific death, defined as the underlying cause of death recorded on the death certificate. The web table shows the causes of death for which we examined associations, together with the international classification of diseases $7,8,9$, and 10 codes we used to define these causes.

\section{Statistical analysis}

When different sons had the same mother or the same father, one child was chosen at random to avoid violation of independence assumptions. We then examined the distribution of parental education, occupational and social class, and health variables in groups defined by quintiles of offspring BMI and estimated logistic and linear regression coefficients for their association with offspring BMI. Logistic regression coefficients were converted to odds ratios.

We next used Cox proportional hazards regression models to estimate hazard ratios (HRs) for all cause and cause specific parental mortality per standard deviation of offspring BMI. Analyses were censored at the earlier of parents' emigration date (when this was known) and 31 December 2001. All models used parents' age as the time axis, with entry at the child's date of birth; therefore, all analyses are controlled for parents' age. We also controlled for parents' educational level and occupational social class. The proportion of mothers with information missing for education was 9\% and for social class was 53\% (including those not classified; for example, housewives and students), whereas the corresponding proportions for fathers were $10 \%$ and $21 \%$.

We examined the linearity of associations in two ways. Firstly, we included a term for the square of offspring BMI in the Cox regression models, and hence estimated the best quadratic association between offspring BMI and the log hazard of each cause of mortality. The $\mathrm{P}$ value corresponding to the term for $\mathrm{BMI}^{2}$ was reported as a test of non-linearity. Secondly, we divided the distribution of offspring BMI into deciles and estimated the HR in each decile group (using the fifth decile as the reference group). We graphed these HRs in order to display the shape of the relationship between offspring BMI and each cause of mortality.

Measures of both paternal and offspring BMI were available in 72815 father-son pairs (2030 paternal deaths). We re-estimated the association of fathers' BMI with all cause mortality, cardiovascular disease, and non-cardiovascular mortality using this restricted dataset, and compared these findings with the

\begin{tabular}{|c|c|c|c|c|c|c|c|c|c|}
\hline \multirow[b]{2}{*}{$\begin{array}{l}\text { Quintile of } \\
\text { offspring BMI }\end{array}$} & \multicolumn{2}{|c|}{ Offspring } & \multicolumn{5}{|c|}{ Fathers } & \multicolumn{2}{|c|}{ Mothers } \\
\hline & $\begin{array}{c}\text { Mean BMI } \\
\left(\mathrm{kg} / \mathrm{m}^{2}\right)\end{array}$ & $\begin{array}{c}\text { Proportion who } \\
\text { smoked at } \\
\text { conscription (\%)* }\end{array}$ & $\begin{array}{c}\text { Mean age at birth } \\
\text { of offspring } \\
\text { (years) }\end{array}$ & $\begin{array}{c}\text { Mean BMI } \\
\left(\mathrm{kg} / \mathrm{m}^{2}\right) \dagger\end{array}$ & $\begin{array}{l}\text { Proportion who } \\
\text { smoked at } \\
\text { conscription } \\
(\%) \ddagger\end{array}$ & $\begin{array}{l}\text { Proportion } \\
\text { educated for } \\
\text { more than } \\
10 \text { years }(\%)\end{array}$ & $\begin{array}{c}\text { Mean systolic } \\
\text { blood pressure at } \\
\text { conscription } \dagger \\
(\mathrm{mm} \mathrm{Hg})\end{array}$ & $\begin{array}{l}\text { Mean age } \\
\text { birth of } \\
\text { offspring } \\
\text { (years) }\end{array}$ & $\begin{array}{l}\text { Proportion } \\
\text { educated for } \\
\text { more than } \\
10 \text { years }(\%)\end{array}$ \\
\hline $1 \mathrm{st}$ & 18.5 & 62.5 & 30.9 & 20.2 & 61.1 & 46.4 & 126.1 & 27.6 & 36.2 \\
\hline 2nd & 20.2 & 59.5 & 30.6 & 20.7 & 63.2 & 47.7 & 126.2 & 27.5 & 38.5 \\
\hline $3 \mathrm{rd}$ & 21.3 & 57.6 & 30.5 & 21.0 & 62.9 & 47.6 & 126.6 & 27.4 & 39.0 \\
\hline 4th & 22.7 & 54.7 & 30.4 & 21.5 & 62.9 & 46.4 & 126.9 & 27.3 & 38.6 \\
\hline 5th & 26.2 & 56.3 & 30.3 & 22.2 & 66.4 & 40.9 & 127.4 & 27.1 & 35.3 \\
\hline $\begin{array}{l}\text { Regression } \\
\text { coefficient per } \\
\mathrm{kg} / \mathrm{m}^{2}(95 \% \mathrm{Cl})\end{array}$ & - & - & $\begin{array}{c}-0.055(-0.060 \text { to } \\
-0.051)\end{array}$ & $\begin{array}{l}0.215(0.209 \\
\text { to } 0.220)\end{array}$ & - & - & $\begin{array}{c}0.155(0.131 \text { to } \\
0.180)\end{array}$ & $\begin{array}{l}-0.059 \\
(-0.063 \text { to } \\
-0.056)\end{array}$ & - \\
\hline $\begin{array}{l}\text { Odds ratio per } \\
\mathrm{kg} / \mathrm{m}^{2}(95 \% \mathrm{Cl})\end{array}$ & - & $\begin{array}{c}0.967(0.958 \text { to } \\
0.976)\end{array}$ & - & - & $\begin{array}{c}1.025(1.015 \text { to } \\
1.035)\end{array}$ & $\begin{array}{c}0.967(0.958 \text { to } \\
0.976)\end{array}$ & - & - & $\begin{array}{c}0.989(0.987 \text { to } \\
0.990)\end{array}$ \\
\hline
\end{tabular}

*Subset with smoking data $(\mathrm{n}=28545)$.

†Subset with conscription data $(n=72824)$.

$\ddagger$ Subset with smoking data $(n=16906)$. 
association of fathers' mortality with sons' BMI. We then used Poisson regression analyses with follow-up time split on the basis of age group to confirm the results of the Cox regression analyses. Finally, we used offspring BMI as an instrumental variable to estimate the causal association between father's BMI and mortality. These analyses used the Stata qvf command to estimate Poisson regression models with instrumental variables. ${ }^{28}$

\section{RESULTS}

The final dataset analysed contained information on 1018012 mother-son pairs (122677 maternal deaths) and 1004617 father-son pairs (242126 paternal deaths). Characteristics of the offspring and parents according to quintile of offspring BMI are presented in table 2. The strongest association between offspring BMI and parental characteristics was between offspring BMI and mean BMI of the father (regression coefficient $0.215,95 \%$ CI 0.209 to 0.220 ; the BMI of mothers was not available). Offspring with a higher BMI had mothers and fathers who were slightly younger on average at the time of their birth and were less likely to have spent more than ten years in full time education than the parents of offspring with a lower BMI. In addition, offspring with higher BMI were less likely to smoke than those with a lower BMI, but had fathers who were more likely to smoke and had lower blood pressure.

\section{Association of offspring BMI with all cause and cause} specific mortality in mothers and fathers

The standard deviation of offspring BMI was $2.916 \mathrm{~kg} /$ $\mathrm{m}^{2}$. Table 3 presents mortality HRs per standard deviation change in offspring BMI. Both mothers' and fathers' all cause mortality was related to the offspring BMI (HR for offspring BMI adjusted by age $1.06,95 \%$ confidence interval 1.06 to $1.07 ; \mathrm{P}<0.001$

\begin{tabular}{|c|c|c|c|c|}
\hline & \multirow[b]{2}{*}{$\begin{array}{c}\text { Number of } \\
\text { deaths }\end{array}$} & \multicolumn{2}{|c|}{ Hazard ratio $(95 \% \mathrm{Cl})$} & \multirow[b]{2}{*}{$\begin{array}{c}\text { Test of non- } \\
\text { linearity* }\end{array}$} \\
\hline & & Adjusted for parental age & $\begin{array}{l}\text { Adjusted for parental age, social } \\
\text { class, and education }\end{array}$ & \\
\hline \multicolumn{5}{|l|}{ Mothers ( $n=1018012)$} \\
\hline All cause & 122627 & 1.06 (1.06 to 1.07$) ; P<0.001$ & 1.06 (1.05 to 1.06 ); $P<0.001$ & $<0.001$ \\
\hline Diseases of the circulatory system & 39062 & 1.12 (1.11 to 1.13 ); P<0.001 & 1.11 (1.09 to 1.12 ); P<0.001 & $<0.001$ \\
\hline Coronary heart disease & 18783 & 1.15 (1.14 to 1.17$) ; \mathrm{P}<0.001$ & 1.14 (1.12 to 1.16$) ; P<0.001$ & $<0.001$ \\
\hline Stroke & 10930 & 1.04 (1.02 to 1.07$) ; P<0.001$ & 1.04 (1.02 to 1.06$) ; P<0.001$ & $<0.001$ \\
\hline Diabetes & 1987 & 1.36 (1.31 to 1.41$) ; P<0.001$ & 1.34 (1.29 to 1.39$) ; P<0.001$ & 0.98 \\
\hline Not circulation related & 83565 & 1.04 (1.03 to 1.05$) ; \mathrm{P}<0.001$ & 1.04 (1.03 to 1.04$) ; P<0.001$ & $<0.001$ \\
\hline Respiratory diseases & 5890 & 1.05 (1.02 to 1.08$) ; \mathrm{P}<0.001$ & 1.04 (1.02 to 1.07$) ; P=0.002$ & 0.009 \\
\hline Cancer & 52686 & 1.05 (1.04 to 1.05$) ; \mathrm{P}<0.001$ & 1.04 (1.03 to 1.05$) ; \mathrm{P}<0.001$ & 0.039 \\
\hline Lung cancer & 5931 & 1.12 (1.09 to 1.15$) ; \mathrm{P}<0.001$ & 1.11 (1.09 to 1.14 ); P<0.001 & 0.22 \\
\hline Breast cancer & 6103 & 0.97 (0.94 to 0.99$) ; \mathrm{P}=0.017$ & 0.96 (0.94 to 0.99); $P=0.006$ & 0.11 \\
\hline Colon cancer & 3889 & 1.04 (1.00 to 1.07$) ; \mathrm{P}=0.033$ & 1.03 (1.00 to 1.07$) ; P=0.047$ & 0.36 \\
\hline Stomach cancer & 2161 & 1.03 (0.99 to 1.08$) ; P=0.19$ & 1.02 (0.98 to 1.06$) ; P=0.41$ & 0.56 \\
\hline Kidney cancer & 1205 & 1.08 (1.03 to 1.15$) ; \mathrm{P}=0.005$ & 1.08 (1.02 to 1.14$) ; P=0.010$ & 0.052 \\
\hline External causes & 8653 & 0.97 (0.95 to 0.99$) ; P=0.015$ & 0.96 (0.94 to 0.98); P<0.001 & 0.14 \\
\hline Suicide & 3686 & 0.94 (0.90 to 0.97); P<0.001 & 0.92 (0.89 to 0.95$) ; P<0.001$ & 0.88 \\
\hline \multicolumn{5}{|l|}{ Fathers $(n=1004$ 617) } \\
\hline All cause & 242104 & 1.06 (1.05 to 1.06 ); P<0.001 & 1.05 (1.04 to 1.05 ); P<0.001 & $<0.001$ \\
\hline Diseases of the circulatory system & 109831 & 1.09 (1.08 to 1.09); P<0.001 & 1.08 (1.07 to 1.08$) ; \mathrm{P}<0.001$ & $<0.001$ \\
\hline Coronary heart disease & 72049 & 1.10 (1.09 to 1.11 ); P<0.001 & 1.08 (1.08 to 1.09 ); P<0.001 & $<0.001$ \\
\hline Stroke & 17981 & 1.05 (1.03 to 1.07); P<0.001 & 1.04 (1.03 to 1.06 ); P<0.001 & 0.037 \\
\hline Diabetes & 3416 & 1.19 (1.15 to 1.23$) ; P<0.001$ & 1.17 (1.14 to 1.21$) ; P<0.001$ & 0.11 \\
\hline Not circulation related & 132273 & 1.03 (1.03 to 1.04 ); P<0.001 & 1.03 (1.02 to 1.03 ); P<0.001 & $<0.001$ \\
\hline Respiratory diseases & 11348 & 1.02 (1.00 to 1.04$) ; \mathrm{P}=0.048$ & 1.01 (0.99 to 1.03$) ; P=0.53$ & $<0.001$ \\
\hline Cancer & 67513 & 1.04 (1.03 to 1.05$) ; \mathrm{P}<0.001$ & 1.04 (1.03 to 1.05 ); P<0.001 & $<0.001$ \\
\hline Lung cancer & 12809 & 1.03 (1.02 to 1.05$) ; \mathrm{P}<0.001$ & 1.02 (1.01 to 1.04$) ; P=0.010$ & $<0.001$ \\
\hline Prostate cancer & 5810 & 1.00 (0.97 to 1.03$) ; P=0.97$ & 1.00 (0.97 to 1.03$) ; P=0.99$ & 0.31 \\
\hline Colon cancer & 4843 & 1.03 (1.00 to 1.06$) ; P=0.070$ & 1.03 (1.00 to 1.06$) ; P=0.050$ & 0.18 \\
\hline Stomach cancer & 4429 & 1.05 (1.02 to 1.09$) ; \mathrm{P}<0.001$ & 1.04 (1.01 to 1.07$) ; P=0.007$ & 0.97 \\
\hline Kidney cancer & 2301 & 1.07 (1.02 to 1.11$) ; P=0.002$ & 1.06 (1.02 to 1.11$) ; P=0.003$ & 0.70 \\
\hline External causes & 24710 & 1.01 (1.00 to 1.02$) ; \mathrm{P}=0.073$ & 0.99 (0.98 to 1.00$) ; \mathrm{P}=0.070$ & $<0.001$ \\
\hline Suicide & 9420 & 0.99 (0.97 to 1.01 ); $P=0.57$ & 0.97 (0.95 to 0.99$) ; \mathrm{P}=0.012$ & 0.001 \\
\hline
\end{tabular}

* $\mathrm{P}$ value associated with quadratic term for offspring $\mathrm{BMI}$ added to adjusted model. 
Table 4 | Hazard ratios $(95 \% \mathrm{Cl})$ for fathers' all cause and cause specific mortality per standard deviation of offspring conscription BMI and fathers' own BMI

\begin{tabular}{|c|c|c|c|c|c|}
\hline & $\begin{array}{c}\text { Offspring BMI (adjusted for } \\
\text { age) }\end{array}$ & $\begin{array}{c}\text { Offspring BMI (adjusted for } \\
\text { age, social class, and } \\
\text { education) }\end{array}$ & $\begin{array}{l}\text { Fathers' BMI (adjusted for } \\
\text { age) }\end{array}$ & $\begin{array}{c}\text { Fathers' BMI (adjusted for } \\
\text { age, social class, and } \\
\text { education) }\end{array}$ & $\begin{array}{l}\text { Instrumental variable } \\
\text { estimation for fathers' BMI } \\
\text { (adjusted for age, social class } \\
\text { and education) }\end{array}$ \\
\hline All cause & 1.04 (1.00 to 1.08$) ; P=0.064$ & 1.03 (0.99 to 1.07$) ; P=0.144$ & 1.10 (1.05 to 1.16$) ; P<0.001$ & 1.09 (1.04 to 1.15$) ; P=0.001$ & 1.16 (0.96 to 1.39$) ; \mathrm{P}=0.120$ \\
\hline \multicolumn{6}{|l|}{ Cause specific } \\
\hline $\begin{array}{l}\text { Cardiovascular } \\
\text { disease related }\end{array}$ & 1.14 (1.05 to 1.25$) ; P=0.003$ & 1.13 (1.04 to 1.24$) ; P=0.006$ & 1.47 (1.33 to 1.64$) ; \mathrm{P}<0.001$ & 1.45 (1.31 to 1.61$) ; P<0.001$ & 1.82 (1.17 to 2.83 ); $\mathrm{P}=0.008$ \\
\hline $\begin{array}{l}\text { Not Cardiovascular } \\
\text { disease related }\end{array}$ & $1.02(0.97$ to 1.06$) ; P=0.462$ & 1.01 (0.97 to 1.05$) ; P=0.680$ & 1.04 (0.98 to 1.09 ); $\mathrm{P}=0.210$ & 1.02 (0.97 to 1.08$) ; P=0.411$ & 1.06 (0.86 to 1.30$) ; P=0.591$ \\
\hline
\end{tabular}

disease related

Analyses based on father-son pairs with BMI measured in both individuals ( $\mathrm{n}=72 \mathrm{815}$ ). The $\mathrm{F}$ test for the strength of offspring BMI as instrument for own BMI is 6356 .

and $1.06,1.05$ to $1.06 ; \mathrm{P}<0.001$, respectively). Adjustment for parental age, social class, and education made little difference to the association $(1.06,1.05$ to 1.06 ; $\mathrm{P}<0.001$ for mothers and $1.05,1.04$ to $1.05 ; \mathrm{P}<0.001$ for fathers).

Death from diabetes, coronary heart disease, and kidney cancer had the strongest positive associations with offspring BMI among both mothers and fathers. Lung cancer mortality was elevated in mothers whose offspring had a higher BMI (1.12, 1.09 to 1.15; $\mathrm{P}<0.001)$, whereas the strength of this association among fathers was much weaker $(1.03,1.02$ to 1.05 ; $\mathrm{P}<0.001)$. Offspring BMI was positively associated with mortality from respiratory diseases for mothers $(1.05,1.02$ to $1.08 ; \mathrm{P}<0.001)$ and less so for fathers (1.02, 1.00 to $1.04 ; \mathrm{P}=0.048)$, which contrasts to reports of strong inverse associations of own BMI with respiratory disease mortality risk in previous studies.

There was an inverse association between offspring $\mathrm{BMI}$ and maternal mortality from breast cancer $(0.97$, 95\% CI 0.94 to $0.99 ; \mathrm{P}=0.017)$ and from external causes $(0.97,0.95$ to $0.99 ; \mathrm{P}=0.015)$, in particular suicide $(0.94,0.90$ to $0.97 ; \mathrm{P}<0.001)$.

We examined whether the association of breast cancer mortality with offspring BMI varied according to age of death by examining the offspring BMI-maternal breast cancer mortality association in three maternal age groups: less than 50 years old; 50 to less than 60 years old; and 60 years or older. An interaction between age of death from breast cancer and offspring BMI was found $(\mathrm{P}=0.002)$. The association of breast cancer mortality risk with offspring BMI was weakly positive in women who died at age 60 years or older (1.02, 0.98 to 1.07$)$, weakly negative in those aged 50-59 years at death $(0.95,0.90$ to 0.99$)$, and more strongly negative in those aged less than 50 years at death $(0.92,0.88$ to 0.97$)$.

Statistical tests of deviation from linearity had considerable power, even for relatively minor departures from linearity. Inspection of the hazard ratios by decile of offspring BMI showed that the non-linearity in associations of offspring BMI with parental morality was generally owing to more marked associations between parental mortality and offspring BMI in the top half of the BMI distribution, rather than any notable increase in mortality in parents with offspring at the lower end of the BMI distribution (see web appendices A and B).
Offspring BMI as an instrumental variable for own BMI in father-son pairs

We examined associations of all cause, cardiovascular disease related, and non-cardiovascular disease related mortality with both own BMI and offspring BMI for the 72815 men who had their measurements taken when conscripts and who also had sons who had measurements taken as conscripts. Table 4 shows estimated hazard ratios per standard deviation of offspring BMI both from conventional multivariable Cox models of the association between own BMI and mortality outcomes and from analyses that used offspring BMI as an instrumental variable for own BMI.

Mortality not related to cardiovascular disease was not strongly associated with either own or offspring BMI (HR 1.04, 95\% CI 0.98 to $1.09 ; \mathrm{P}=0.210$ and $1.02,0.97$ to $1.06 ; \mathrm{P}=0.462$, respectively), whereas all cause and cardiovascular disease related mortality were positively associated with both own and offspring BMI (all cause: $1.10,1.05$ to $1.16 ; \mathrm{P}<0.001$ and 1.04 , 1.00 to $1.08 ; \mathrm{P}=0.064$, respectively; cardiovascular disease related: $1.47,1.33$ to $1.64 ; \mathrm{P}<0.001$ and $1.14,1.05$ to $1.25 ; \mathrm{P}=0.003$, respectively).

The association of own BMI with all cause mortality was of greater magnitude when estimated using offspring BMI as an instrumental variable than when estimated directly $(1.16,0.96$ to $1.39 ; \mathrm{P}=0.120 \mathrm{v} 1.09,1.04$ to $1.15 ; \mathrm{P}=0.001)$. A similar pattern was seen with the effect of BMI on cardiovascular disease mortality (1.82, 1.17 to $2.83 ; \mathrm{P}=0.008 \mathrm{v} 1.45,1.31$ to 1.61 ; $\mathrm{P}<0.001)$. However, the precision of the effect estimates was low.

\section{DISCUSSION}

Principal findings

Our analysis of the effects of BMI on mortality using offspring BMI as an indicator of adult BMI shows positive associations between offspring BMI and parental mortality from cardiovascular disease, diabetes, and some cancers. We do not find inverse associations between offspring BMI and risk of mortality from respiratory disease and lung cancer, which would be anticipated on the basis of previous studies that found own BMI to be strongly inversely related to mortality from these conditions. ${ }^{11}$ Use of offspring BMI as an instrumental variable for own BMI suggests that previous studies have underestimated the strength of the 
positive association between own BMI and all cause and cardiovascular disease mortality.

\section{Comparison with other studies}

Confounding and reverse causality are leading concerns when estimating the magnitude of the association between BMI and mortality. ${ }^{1}$ The two main approaches that have been used to address these potential biases are excluding deaths occurring in the first few years of follow-up and accounting for potential confounding factors in analyses by adjustment or stratification, but these approaches have severe limitations. Another technique to reduce the impact of reverse causality is the use of BMI measured early in life, when BMI is less likely to be affected by adverse health conditions. This approach has been used to study the nature of the association between BMI and socioeconomic position. ${ }^{2930}$ Large cohort studies or meta-analyses of smaller studies in which BMI was measured in childhood and adolescence found associations between pre-adult BMI and all cause mortality, ${ }^{31-33}$ coronary heart disease mortality and morbidity, ${ }^{3435}$ and other cause specific mortality. ${ }^{3132}$ Smaller studies have not found these patterns, ${ }^{36}$ but their power was too limited to support any reliable claims on this issue.

The pattern of associations between offspring BMI and cause specific mortality in our study is generally similar to that found between own BMI and cause specific mortality in many other studies. The cause of death most strongly associated with offspring BMI in our study was diabetes; a similar relation is seen in studies of own BMI. ${ }^{1137}$ Death from cardiovascular disease also had a strong positive association with offspring BMI in this study, and with own BMI in this and many other studies. ${ }^{13738}$ Our findings suggest that the association of BMI with cardiovascular disease mortality may be underestimated by the direct evaluation of the strength of associations between low BMI and cardiovascular disease outcomes in cohort studies. The reason for such underestimation could be that early stages of illness are associated with reduced BMI but increased risk of death from cardiovascular disease. In addition, there could be negative confounding-lower BMI is associated with detrimental exposures such as cigarette smoking and heavy alcohol consumption, both of which increase the risk of cardiovascular disease. ${ }^{11}$ Our own data illustrate this point, as cigarette smoking was associated with lower BMI.

The strongest inverse association between BMI and mortality in conventional observational studies is with respiratory disease mortality. ${ }^{11}$ Previous research led to the suggestion that this link could not be explained by reverse causality or confounding. ${ }^{39}$ Our use of offspring BMI - that is, a measure that is not influenced by reverse causation and less influenced by confounding - as a proxy for own BMI suggests that the inverse association between BMI and respiratory disease mortality is non-causal. Among men in our study, there was no consistent association between respiratory disease mortality and offspring BMI. The association among women was positive rather than negative, presumably reflecting an association of maternal smoking with offspring BMI.

Our findings with respect to respiratory disease mortality are in line with those of a study by Bjorge et al that minimised reverse causation and confounding by using BMI in adolescence as a predictor of respiratory disease mortality. ${ }^{32}$ This study found an overall positive association between BMI and respiratory disease mortality over more than 40 years of follow-up, and evidence of a much smaller increased risk in the low BMI group than in observational studies that measured $\mathrm{BMI}$ in middle age. Clearly reverse causation - in this case, illness influencing BMI-will not be entirely absent in an adolescent sample, but would be much less marked than when measurements are taken in middle age. Thus both our findings with respect to offspring BMI and Bjorge and colleagues' findings with respect to $\mathrm{BMI}$ measured in adolescence suggest that the association between BMI and respiratory disease mortality may indeed be the result of reverse causation and confounding.

Among men, kidney cancer had the strongest positive association with offspring BMI of any cancer we examined, similar to findings in other studies of own BMI and site specific cancer mortality. ${ }^{113340}$ Among the mothers in this study, higher offspring BMI was associated with a higher risk of lung cancer mortality. This is presumably because maternal smoking is positively associated with offspring BMI, as also reflected in higher respiratory disease mortality among mothers whose offspring had higher BMI. In line with the respiratory disease mortality findings, fathers' lung cancer mortality was only weakly positively associated with BMI, suggesting less of an association between fathers' smoking and offspring BMI. This albeit weak association could be generated by assortative mating; that is, individuals tend to mate with individuals who are similar to themselves in some respect, in this case smoking status. These positive associations are in stark contrast to the inverse association between BMI and lung cancer mortality that have generally been reported from conventional observational studies. ${ }^{11}$

Analyses of the association between offspring BMI and breast cancer mortality by age of death showed that higher offspring BMI had a protective effect among women under 60 years of age. This relation was reversed in women who died when they were aged 60 or over; that is, in those who were most likely to have postmenopausal onset breast cancer. These findings are in line with those of other studies, which have found a similar age related reversal of the direction of association between own BMI and breast cancer risk $^{40}$ and mortality. ${ }^{114041}$ This similarity provides reassuring evidence that offspring BMI serves as a useful indicator of own BMI when studying these associations, as it is difficult to see how such a pattern could be generated by bias.

We suggest that sex differences in findings with respect to offspring BMI and mortality illustrate an anticipated problem in using offspring BMI as a 


\section{WHAT IS ALREADY KNOWN ON THIS TOPIC}

High BMI is associated with higher rates of mortality from cardiovascular causes, diabetes, and some cancers

Low BMI is associated with increased mortality from other causes, such as respiratory

disease and lung cancer

It is uncertain whether the apparent adverse influence of low BMI on mortality is causal or owing to confounding, reverse causation, or both

\section{WHAT THIS STUDY ADDS}

Our analysis using offspring BMI as an indicator of parental BMI shows associations between high BMI and mortality from cardiovascular disease, diabetes, and some cancers

Use of offspring BMI as an indicator of parental BMI does not, however, suggest that low BMI is associated with increased risk of respiratory disease and lung cancer mortality

Taken together, these data suggest that the adverse influence of higher BMI and obesity in a population is of greater magnitude than previously thought

proxy for own BMI- that in women, factors that might affect offspring in utero and modify subsequent BMI may also influence the health outcomes and mortality risk of the mother. Smoking is one such factor, because smoking during pregnancy has been linked to high BMI among offspring in many studies,${ }^{4243}$ an association that strengthens with age. ${ }^{43}$ A recent study showed that in contemporary children, the strength of the association between paternal smoking and offspring BMI in childhood was similar to that of maternal smoking, ${ }^{41}$ suggesting common confounding by smoking for both mothers and fathers. However, this may not have been true several decades ago, when the social distribution of smoking in men and women was different and mothers may have had a stronger influence on the growth trajectories of their offspring than fathers.

Among mothers, and much less so among fathers, higher offspring BMI was associated with lower mortality from external causes, and in particular from suicide. A stronger inverse association of own BMI with suicide in women compared with men was found in a US study ${ }^{44}$ and in two separate Norwegian studies. ${ }^{3245}$ Other studies of men and women combined ${ }^{46}$ and of men only (Swedish conscripts ${ }^{47}$ and US health professionals ${ }^{48}$ ) have also found inverse associations between own BMI and suicide.

As in one previous study, ${ }^{22}$ we used offspring BMI as an instrumental variable for own BMI. Other studies have used sibling obesity, ${ }^{49}$ and area based indicators ${ }^{50}$ (for example, mean BMI in health authority and prevalence of obesity in health authority) as instrumental variables for own BMI. These studies have not examined mortality or morbidity as health outcomes. More powerful instrumental variables for BMI may be provided by the identification of genetic variants robustly associated with BMI, for example genetic variation in the $F T O$ gene.${ }^{51} \mathrm{~A}$ Mendelian randomisation approach - which is predicated on the demonstration that genetic variation is unrelated to potential confounders and will not be influenced by reverse causation - can be used to determine the association between BMI and health outcomes. ${ }^{5253}$ Hence, if the observed association between a genetic variation in the FTO gene and mortality is greater than that expected given FTO-BMI and BMI-mortality associations, the BMImortality association is potentially underestimated. In proof of principle studies, this method generated associations between $F T O$ variation and cardiovascular risk factors. ${ }^{5455}$ However, only one study to date has used this method to explore the BMI-cancer association, without definitive findings. ${ }^{56}$ Very large sample sizes are required to obtain adequate statistical power for mortality or disease end points.

\section{Strengths and limitations of the study}

The strengths of our study are its very large size, prospective design, and population based nature, allowing precise and largely unbiased estimation of the association between offspring BMI and a large range of causes of death.

The limitations to the approach taken in this study largely relate to offspring BMI being potentially associated with confounding factors. In particular, use of offspring BMI as a proxy for own BMI is problematic with respect to maternal causes of death related to factors that have intrauterine influences on offspring BMI. This is discussed above with respect to maternal smoking. A further illustration of this issue is diabetes mortality. It is well known that glucose intolerance and diabetes in mothers is associated with higher offspring BMI. ${ }^{57}$ The considerably greater association of offspring BMI with diabetes mortality of mothers compared with diabetes mortality of fathers in our study illustrates this. However, the positive association of paternal mortality from diabetes with offspring BMI, which is considerably stronger than the association with any other cause of death, illustrates that offspring BMI does have value as an indicator of own BMI.

Another example of potential confounding is alcohol consumption, which is inversely associated with offspring birth weight ${ }^{58}$ and is linked to an increased risk of suicide ${ }^{59}$ Although we know of no direct evidence on this issue, it is possible that maternal alcohol consumption and depression are associated with lower offspring BMI and, through this relation, generate an association between low offspring BMI and maternal suicide risk. We therefore attach greater credence to the associations between offspring BMI and paternal mortality than to those between offspring BMI and maternal mortality.

There is some evidence of residual confounding in the fathers in the plots of respiratory disease and lung cancer mortality against decile of BMI (see web appendix B). A small increase in mortality can be seen among fathers who have offspring in the lowest BMI groups, consistent with the higher rates of smoking in the fathers with offspring who have a low BMI. However, these small increases in mortality only at the lower end of the BMI distribution contrast markedly with the substantial increases and overall strong negative association seen between BMI and mortality from these causes in conventional observational studies. ${ }^{1{ }^{143}}$ 
Another potential limitation is that the sample in which we directly compared paternal BMI and offspring BMI is a relatively small subsample of the main dataset, and thus only permitted estimation of all cause, cardiovascular disease related, and noncardiovascular disease related mortality. With a larger dataset, it would be possible to directly associate causes of death that have been particularly controversial in their link to BMI-such as respiratory disease and lung cancer - with both parental and offspring BMI.

Our study assumes that BMI has the same influence on outcomes regardless of whether it is influenced by genetic or lifestyle factors. This assumption seems valid, however, because evidence suggests that genetic variants linked to BMI are associated with other outcomes, such as blood pressure and bone mineral density, to a similar degree as that predicted by the association of BMI (both its genetic and environmental component) with such outcomes. ${ }^{545560}$

Finally, we have not adapted the instrumental variable analysis to the non-linear situation. ${ }^{61}$ However, the purpose of our study was to provide a simple estimate of the extent to which causal associations of BMI and cardiovascular disease could be underestimated by naive analyses.

\section{Conclusions}

For some causes of death, patterns of associations between offspring BMI and mortality were similar to those seen for own BMI in previous studies. These findings suggest that offspring BMI serves as a useful proxy measure of own BMI in such analyses. There were two exceptions to this general pattern: firstly, in situations where there is an anticipated effect of antenatal exposures that are associated with both offspring $\mathrm{BMI}$ and maternal mortality; and secondly, for respiratory disease and lung cancer mortality in fathers, the inverse associations observed in conventional epidemiological studies are not recapitulated in our analysis. Our findings suggest that the apparent adverse consequences of low BMI on respiratory disease and lung cancer mortality may be overstated, whereas the adverse consequences of higher BMI on cardiovascular disease mortality may be substantially underestimated.

These conclusions have important implications for public health practice because they suggest that reducing population levels of overweight and obesity (or preventing their rise) will have a considerable benefit to population health. Suggestions to the contrary are probably misguided..$^{1-4} 1415$

Contributors: GDS developed the idea for this study. FR and PT constructed the dataset, and JACS carried out the statistical analysis. GDS led the writing of the paper, with substantial contributions from JACS, AF, PT, DAL, and FR. FR, JACS, and GDS act as guarantors for the paper. Funding: The Medical Research Council (G0600705) and the University of Bristol provide core funding for the Medical Research Council Centre of Causal Analyses in Translational Epidemiology. JACS and DAL were also funded by Medical Research Council collaborative project grant G0601625. AF is funded by a Medical Research Council research fellowship. The views expressed in this paper are those of the authors and not necessarily those of any funding body or others whose support is acknowledged. The funders had no role in study design, data collection and analysis, decision to publish, or preparation of the manuscript.

Competing interests: None declared.

Ethical approval: The study was approved by the Regional Ethical Review Board, Stockholm Sweden.

Data sharing: No additional data available.

1 Andres R. Beautiful hypotheses and ugly facts: the BMI-mortality association. Obes Res 1999;7:417-9.

2 Andres R. Effect of obesity on total mortality. Int J Obes 1980;4:381-6.

3 Sorensen TI. Weight loss causes increased mortality: pros. Obes Rev 2003;4:3-7.

4 Campos P. The obesity myth: why America's obsession with weight is hazardous to your health. Gotham Books, 2004.

5 Adams KF, Schatzkin A, Harris TB, Kipnis V, Mouw T, Ballard-Barbash R, et al. Overweight, obesity, and mortality in a large prospective cohort of persons 50 to 71 years old. N Engl J Med 2006;355:763-78.

6 Jarrett RJ, Shipley MJ, Rose G. Weight and mortality in the Whitehall Study. BMJ 1982;285:535-7.

7 Katzmarzyk PT, Craig CL, Bouchard C. Underweight, overweight and obesity: relationships with mortality in the 13-year follow-up of the Canada Fitness Survey. J Clin Epidemiol 2001;54:916-20.

8 Lew EA, Garfinkel L. Variations in mortality by weight among 750,000 men and women. J Chronic Dis 1979;32:563-76.

9 McGee DL. Body mass index and mortality: a meta-analysis based on person-level data from twenty-six observational studies. Ann Epidemiol 2005;15:87-97.

10 Rissanen A, Heliovaara M, Knekt P, Aromaa A, Reunanen A, Maatela Weight and mortality in Finnish men. J Clin Epidemiol 1989;42:781-9.

11 Prospective Studies Collaboration. Body-mass index and causespecific mortality in 900,000 adults: collaborative analyses of 57 prospective studies. Lancet 2009;373:1083-96.

12 Sorlie P, Gordon T, Kannel WB. Body build and mortality: the Framingham study. JAMA 1980;243:1828-31.

13 Pischon T, Boeing H, Hoffmann K, Bergmann M, Schulze MB, Overvad K, et al. General and abdominal adiposity and risk of death in Europe. N Engl J Med 2008;359:2105-20.

14 Flegal KM, Graubard BI, Williamson DF, Gail MH. Cause-specific excess deaths associated with underweight, overweight, and obesity. JAMA 2007;298:2028-37.

15 Flegal KM, Graubard BI, Williamson DF, Gail MH. Excess deaths associated with underweight, overweight, and obesity. JAMA 2005;293:1861-7.

16 Rose G. The strategy of preventive medicine. Oxford University Press, 1992.

17 Costa D. The measure of man and older age mortality: evidence from the Gould sample. J Econ Hist 2004;64:1-23.

18 Seidell IC, Visscher TL, Hoogeveen RT. Overweight and obesity in th mortality rate data: current evidence and research issues. Med Sci Sports Exerc 1999;31(Suppl 11):S597-S601.

19 Sauvaget C, Ramadas K, Thomas G, Vinoda J, Thara S, Sankaranarayanan R. Body mass index, weight change and mortality risk in a prospective study in India. Int J Epidemiol 2008;37:990-1004.

20 Phillips AN, Davey Smith G. How independent are "independent" effects? Relative risk estimation when correlated exposures are measured imprecisely. J Clin Epidemiol 1991;44:1223-31.

21 Flanders WD, Augestad LB. Adjusting for reverse causality in the relationship between obesity and mortality. Int J Obes (Lond) 2008;32(Suppl 3):S42-S46.

22 Cawley J. An instrumental variables approach to measuring the effect of body weight on employment disability. Health Serv Res 2000;35:1159-79.

23 Lawlor DA, Harbord RM, Sterne JAC, Timpson NJ, Davey Smith G. Mendelian randomization : Using genes as instruments for making causal inferences in epidemiology. Statistics in Medicine 2008;27:1133-63.

24 Davey Smith G, Steer C, Leary S, Ness A. Is there an intrauterine influence on obesity? Evidence from parent child associations in the Avon Longitudinal Study of Parents and Children (ALSPAC). Arch Dis Child 2007;92:876-80.

25 Lake JK, Power C, Cole TJ. Child to adult body mass index in the 1958 British birth cohort: associations with parental obesity. Arch Dis Child 1997;77:376-81.

26 Davey Smith G, Sterne JA, Tynelius P, Rasmussen F. Birth characteristics of offspring and parental diabetes: evidence for the fetal insulin hypothesis. J Epidemiol Community Health 2004:58:126-8.

27 Davey Smith G, Sterne J, Tynelius P, Lawlor DA, Rasmussen F. Birth weight of offspring and subsequent cardiovascular mortality of the parents. Epidemiology 2005;16:563-9. 
28 Hardin JW, Schmiediche H. Instrumental variables, bootstrapping, and generalized linear models. Stata J 2003;3:351-60.

29 Gortmaker SL, Must A, Perrin JM, Sobol AM, Dietz WH. Social and economic consequences of overweight in adolescence and young adulthood. N Engl J Med 1993;329:1008-12.

30 Karnehed NE, Rasmussen F, Hemmingsson T, Tynelius P. Obesity in young adulthood is related to social mobility among Swedish men. Obesity 2008;16:654-8.

31 Engeland A, Bjorge T, Sogaard AJ, Tverdal A. Body mass index in adolescence in relation to total mortality: 32-year follow-up of 227,000 Norwegian boys and girls. Am J Epidemiol 2003;157:517-23.

32 Bjorge T, Engeland A, Tverdal A, Davey Smith G. Body mass index in adolescence in relation to cause-specific mortality: a follow-up of 230,000 Norwegian adolescents. Am J Epidemiol 2008;168:30-7.

33 Neovius M, Sundström J, Rasmussen F. Combined effects of overweight and smoking in late adolescence on subsequent mortality: nationwide cohort study. BMJ 2009;338:b496.

34 Baker JL, Olsen LW, Sorensen TI. Childhood body-mass index and the risk of coronary heart disease in adulthood. $N$ Engl J Med 2007;357:2329-37.

35 Owen CG, Whincup PH, Orfei Q-A, Rudnicka AR, Wathern AK, Kaye SJ, et al. Is body mass index before middle age related to coronary heart disease risk in later life? Evidence from observational studies. Int Journal of Obesity 2009;33:866-77.

36 Lawlor DA, Martin RM, Gunnell D, Galobardes B, Ebrahim S, Sandhu J, et al. Association of body mass index measured in childhood, adolescence, and young adulthood with risk of ischemic heart disease and stroke: findings from 3 historical cohort studies. Am I Clin Nutr 2006;83:767-73.

37 Rogers RG, Hummer RA, Krueger PM. The effect of obesity on overall, circulatory disease- and diabetes-specific mortality. J Biosoc Sci 2003;35:107-29.

38 McGee DL. Body mass index and mortality: a meta-analysis based on person-level data from twenty-six observational studies. Ann Epidemiol 2005;15:87-97.

39 Lopex-Jimenez F. Speakable and unspeakable facts about BMI and mortality. Lancet 2009;373:1055-6.

40 Reeves GK, Pirie K, Beral V, Green J, Spencer E, Bull D for the Million Women Study Collaboration. Cancer incidence and mortality in relation to body mass index in the Million Women Study: cohort study. BMJ 2007;335:1134.

41 Calle EE, Rodriguez C, Walker-Thurmond K, Thun MJ. Overweight, obesity, and mortality from cancer in prospectively studied cohort of US adults. N Engl J Med 2003;348:1625-38.

42 Leary SD, Davey Smith G, Rogers IS, Reilly IJ, Wells ICK, Ness AR. Smoking during pregnancy and offspring fat and lean mass in childhood. Obesity Res 2006;14:2284-93.

43 Power C, Jefferis BJ. Fetal environment and subsequent obesity: a study of maternal smoking. Int J Epidemiol 2002;31:413-9.

44 Kaplan MS, McFarland BH, Huguet N. The relationship of body weight to suicide risk among men and women: results from the US National Health Interview Survey Linked Mortality File. J Nerv Ment Dis 2007;195:948-51.

45 Bjerkeset O, Romundstad P, Evans J, Gunnell D. Association of adult body mass index and height with anxiety, depression, and suicide in the general population: the HUNT study. Am J Epidemiol 2008;167:193-202.

46 Gasse C, Derby LE, Vasilakis C, Jick H. Risk of suicide among users of calcium channel blockers: population based, nested case-control study. BMJ 2000;320:1251.

47 Magnusson P, Rasmussen F, Lawlor D, Tynelius P, Gunnell D. Association of body mass index with suicide mortality: a prospective cohort study of more than one million men. Am J Epidemiol 2005;163:1-8.

48 Mukamal KJ, Kawachi I, Miller M, Rimm EB. Body mass index and risk of suicide among men. Arch Intern Med 2007;167:468-75.

49 Cawley J. The impact of obesity on wages. J Human Resources 2004;39:451-74.

50 Morris S. Body mass index and occupational attainment. Health Econ 2006;25:347-64.

51 Frayling TM, Timpson NJ, Weedon MN, Zeggini E, Freathy RM, Lindgren CM, et al. A common variant in the FTO gene is associated with body mass index and predisposes to childhood and adult obesity. Science 2007;316:889-94.

52 Davey Smith G, Ebrahim S. 'Mendelian randomization': can genetic epidemiology contribute to understanding environmental determinants of disease? Int J Epidemiology 2003;32:1-22.

53 Davey Smith G, Lawlor DA, Harbord R, Timpson N, Day I, Ebrahim S. Clustered environments and randomised genes: a fundamental distinction between conventional and genetic epidemiology. PloS Medicine 2008;4:1985-92.

54 Freathy RM, Timpson NJ, Lawlor DA, Pouta A, Ben-Shlomo Y, Ruokonen A, et al. Common variation in the FTO gene alters diabetesrelated metabolic traits to the extent expected, given its effect on BMI. Diabetes 2008;57:1419-26.

55 Timpson N, Harbord R, Davey Smith G, Zacho J, Tybaerg-Hansen A, Nordestgaard BG. Does greater adiposity increase blood pressure and hypertension risk? Mendelian randomization using FTO/MC4R genotype. Hypertension 2009;54:84-90.

56 Brennan P, McKay J, Moore L, Zaridze D, Mukeria A, Szeszenia-Dabrowska N, et al. Obesity and cancer: Mendelian randomization approach utilizing the FTO genotype. Int J Epidemiol 2009;38:971-4.

57 Dabelea D. The predisposition to obesity and diabetes in offspring of diabetic mothers. Diabetes Care 2007;30:169-74.

58 Jaddoe VWV, Bakker R, Hofman A, Mackenbach JP, Moll HA, Steegers EA, et al. Moderate alcohol consumption during pregnancy and the risk of low birth weight and preterm birth: the generation $\mathrm{R}$ study. Ann Epidemiol 2007;17:834-40.

59 Mukamal KJ, Kawachi I, Miller M, Rimm EB. Drinking frequency and quantity and risk of suicide among men. Soc Psychiatry Psychiatr Epidemiol 2007;42:153-60.

60 Timpson NJ, Sayers A, Davey Smith G, Tobias JH. How does body fat influence bone mass in childhood? A Mendelian randomisation approach. J Bone Miner Res 2009;24:522-33.

61 Terza JV, Bradford WD, Dismuke CE. The use of linear instrumental variables methods in health services research and health economics: a cautionary note. HSR: Health Services Research 2008;43:1102-20.

Accepted: 1 October 2009 